\title{
Relationship of Self and Other in Cultural and Religious Communications
}

\author{
Olga Chistyakova \\ Department of Social Philosophy \\ Faculty of Humanities and Social Sciences \\ Peoples' Friendship University of Russia \\ Miklukho-Maklaya str., 10a \\ Moscow, Russia 117198 \\ E-mail: olgachis@yandex.ru
}

\begin{abstract}
The problem of Self and Other is being discussed in the context of cultural and religious peculiarities of contemporary time. The anthropological consequences of communications are considered from the postmodern features and, in particular, the strangification process. The author discusses religion and possible forms of inter-religious dialogue from the philosophical view of religion. The author considers religion as the utmost wide concept, as "religion in itself", lacking definite references to any religion in particular.
\end{abstract}

Keywords -religious communication; contemporary culture; strangification; Chinese philosophy; God as Other

\section{INTRODUCTION}

The problem of Self and Other has always been and will remain as long as humanity exists.

In a contemporary society, the very notion and role of the "Other" (of the other Human being, first of all) are mostly forced out from the real social communication. The fundamental place of the "Other" is occupied by technology, computers, and social networks. A virtual world became equivalent to the "Other". With the invasion of simulative, illusive and unreal features into the objective human relations, the very possibility of compassion, sympathy, love, mercy and other existential feelings are dislodged from the spiritual and cultural lives. It's impossible to reveal the feelings of compassion and gratitude towards the computers and other kinds of information technologies.

Besides, we have to say that communication and dialogue with the Others cannot be conducted from within Person's self-enclosure, especially in the era of globalization. We are committed to the process of mutual enrichment not only in everyday lives but also in economic, political, scholar activities. We are bound to comprehend ourselves in a process of perceiving the Others (the Strangers), sometimes feeling estranged to ourselves. This process of reciprocal awareness of the essence of human nature, the representatives of phenomenological philosophy titled "strangification". This process is real and objective in the epoch of expanded globalization. If we want to know who we are, we have to conceive the Others (the Strangers) in their depth, ignorance of us, their personal essence and essence of unusual cultures and religious identifications. Simultaneously, it would be the process of self-cognition and self-consciousness through the search of cultural values, personal perception of God and Absolute moral norms.

\section{MODERN AND POSTMODERN INDIVIDUALS}

Contemporary culture needs to be defined. Sometimes the clarification of culture might be taken from the history. In these terms, one of the best elucidations is provided by Martin Buber who characterized the last century as "homelessness", "deprivation", unhappiness, and so on. The modern world has come again to these notions but in a concentrated state. The eras of "homelessness", disorder, uncompassion, when the feelings of loneliness, insecurity, and personal failure have been revived. This is the epoch when deep and insightful philosophical-anthropological doctrines might arise.

Keeping up with the position that the current society is passing the stages of modernity and postmodernity with respective qualitative changes in all the spheres (economic, political, social, cultural), let us note that a modernity individual is an immanent "product" of his own time with the emerging conceptual justifications and narratives, while a postmodern individual bears his own imprint of the history and radically changed condition of society. The transformation dynamics from modernity to postmodernity is a transition to a society having qualitatively different grounds and characteristics in comparison to the previous ones. Deep and accelerating transformations have affected the very nature of an individual: a postmodern individual differs significantly from the modern version of him.

It seems to us that the state of a postmodern society is best described as "homeless" with a sense of abandonment, and this is exactly what M. Buber wrote about. An individual finds himself "not completely at home" in a rapidly changing world characterized by the accelerated flow of social time, deterritorialization of space and culture. Society's dynamic aspiration to the future, vagueness, "liquidity" (Z. Bauman) of reality, infinite circulation of media flows, difficulty of personal identification in an increasingly complex and 
diverse world reveal the problem of individual's life orientation choices.

In the age of modernity an individual and his uniqueness with the whole range of subjective characteristics was concentrated in the definition of "personality". In the age of postmodernity subjectivity dissolves in sociality, that, following J. Baudrillard, also dissolves, transforming into other forms, giving birth to something fundamentally different. "An individual is being socially contextualized, a new functional "man-and-his-environment" unity emerges" $[1 ;$ p. 180].

In comparison to the preceding modernity, individuals of postmodernity are radically different; moreover, they symbolize the changed phenomena of new social life. According to the postmodern thinkers, a subject is divided into many functions, planes, social and personal roles, which are probably connected with the division of social life into different spheres (politics, economy, culture) that weaken, dissolve, mutate, and turn into "ephemeral" (J. Baudrillard) media myths. Language narratives (J-F. Lyotard), interpretations and decoded text messages come into play. Infinite information flows possess the human consciousness. Freedom and substance of an individual fade into the background.

Postmodern society becomes discrete, fragmentary, unified logic breaks. Human life is thus also fragmented: short life periods surface, presenting the immediacy of the present with short-term personal goals. This immediacy, however, even targeted in the future, may be a subject of change at any time.

Sacred and spiritual culture is being gradually replaced in a contemporary "spectacle" social life, in terms of Guy Debord [2], by trends of dissolution of unique personality traits, unification of individuals, de-institutionalization of modern institutions, society atomization, gradual loss of stability and depth of own and family lives and creation of mediatized "unreal reality" (A. Giddens), perceived by human as objective and factual reality.

Such unstable, precarious state of society with radically changed institutional characteristics has led to the fact that the phenomena of social and personal in postmodernity shall be considered from a qualitatively different perspective than in the previous era of late modernity (the late $20^{\text {th }}$ century).

\section{SELF AND OTHER: ANTHROPOLOGICAL}

\section{CONSEQUENCES OF CONTEMPORARY COMMUNICATION}

Let us emphasize that communication in the postmodern era is not the usual social interaction of an individual and the Other (Other person or Other community). The nature of the new communications is specific and also simulative, as the real interpersonal relationships are being often replaced by the relations between individuals and technology, between humans and screens. People gradually get used to this kind of relationships, being brought up by the similarities of social interaction and feeling a deep need for them during their lifetime. Postmodern philosophers called "the end of anthropology" the situation when an individual is found in a state of admiration of communications, existing in the form of "homeostasis" of a man and a machine. J. Baudrillard illustrated clearly this point via spectator in front of a TV screen: "The image of a spectator, contemplating a blank TV screen on a day of a strike, will once be considered one of the most stunning anthropological images of the $20^{\text {th }}$ century" [3; p. 6].

In this kind of contemporary cultures, the fundamental problem of Self-Other relation appears intensified. In our time human is spiritually wasted mostly due to the lack of attention, compassion, love coming from the other people, those, who human is ready to admit into his/her life and make them to the center of personal existence. In that context emerges the actual necessity of returning the "Other" in the philosophical meaning into the social and spiritual life of a person and into the culture.

The renewing of spiritual and socio-cultural life of society, where the main role will belong to the "Other" as a center-personal phenomenon, is the essential objective of the modern world. The renaissance of the "Other" will yield love and all the feelings lost or expropriated by the machines, technology, economic and globalization processes, crisis etc.

Religion plays a tremendous role under these conditions. The "Other" might be viewed as an "other" person, but to some this role might be preoccupied by God. Under the described circumstances, religion might occupy the field left free, i.e. the personal space of a contemporary human, who lost his basis and is forced to submit to both external and internal factors of a sheer being.

Therefore, compassion is not possible without the "Other", without a return to the "Other" into the life of modern man. The life of community must be rebuilt so that the "Other" would enter it as a cultural center of social existence. Since religion has clearly an anthropological sense, they obviously should open doors to the anthropological cultures, even under conditions of secularization processes.

Jean-Paul Sartre, underlining the meaningfulness of "The Stranger" by A. Camus, stressed the real existence of a human with relation with the Stranger in this terrestrial world and awareness of a human being like an objective process. He wrote: "For Camus... the tragedy of human existence lies in the absence of any transcendence... He is not concerned, then, with arranging words so as to suggest an inhuman, indecipherable order; the inhuman is merely the disorderly, the mechanical" [4; p. 88].

The absurd man, who knows only the good things of this world, can comprehend the Stranger (the Other in our context) in the terms of humanity. Nevertheless, Camus pointed out that the Stranger always remains silent. Why? Sartre did not shed the light on this thesis. He just stressed the classical character of the Camus' book, "a clearly orchestrated work, composed about, and against, the absurd" [4; p. 97].

We only can imagine what "the silence" of the Stranger might mean. Possibly, it's a metaphor for the Other, coming from a different culture, religion, society, and even from different discourse. The Other/Stranger feels his "Otherness" 
and would rather be unknowing, unrealized, keeping his own environment and cultural context.

The ideas of strangification are given by the works of postmodernists such as G. Deleuze, J. Derrida, and phenomenologists (E. Levinas, E. Husserl). They appeal to the Self-Other opposition, their differences, and specific characteristic. In order to learn the world and reality in-depth, we need to know the personal Ego, the essence of each person as the Stranger (or the Other). As we have already mentioned, according to Camus and to the phenomenologists, the Stranger is a real person, at the meeting with whom my Self morphs. The relation to the Other is particular, not common. The Stranger (the Other) has been changing in each moment of his life and I become the Stranger for myself while my Self is being in connection with him/them. This is a developing process of mutual enrichment and awareness of each other, of reciprocal alternation, of a practice of having a deal with the differences of the Other (religious, cultural, behavioral, mental and so on).

The relation to the Other is not only the influence on him but also the effects of the said influence on Self. The influence of the Other towards Self in accordance to the experience of the Other alters me and might be crucial. Personal existence is very sensitive and can be destroyed or vice versa - rebuilt just by contacting another human or fleeting glance of the Other.

The question here is: under what circumstances I open myself for the Other and why let him into my life?

Let us refer to the article of a Canadian scholar of Chinese origin Vincent Shen who is reflecting on the strangification process from the position of Confucian altruism and generosity. He points out that the process of strangification greatly reflects the communications in the epoch of globalization, where the latter can be understood as a "historical process of deterritorialization or cross-bordering, in which human universalizability and ontological interconnectedness are to be realized on the planet as a whole" $[5$, p. 1]. He replaces the idea of "the Other" of the French postmodernists and phenomenologists with the idea of "many others". He explained that the "many others" notion is preferable due to its focus on the "concrete ontological context in which we are born, grow up and develop" [5, p. 6]. We live among the many others and have to accept them into our lives and the idea "of many others is more realistic and clear than Levinas' concept of "tiers parts", which means only "the Other of the Other". He emphasized" that in a postmodern world the principal of reciprocity in the relation of Self and Other is insufficient, thus we need a human principle that extends beyond the mere reciprocity. He claims: "The new ethical and social principles... should base themselves on original generosity and strangification as the act of going outside of oneself to many others" [5, p. 7]. The author suggests using the Confucian terms Ren and Shu in order to establish a perfect response to another on both the ontological and on the ethical levels. From his point of view, Ren denotes the internal relations among human beings and all living things, so the notion Shu "can extend to larger realms of existence beyond themselves, to the others, to family, to social community, to the state, to all under heaven" [5, p. 7].

Referring solely to the origin of Ren, which is historically connected to the thought of Confucius, we should mention that Ren is a moral core of Confucianism and of Ancient Chinese culture alike. Confucius conception of Ren includes the issues of love to all people, duties to old brother and parents, esteem and devotion to supreme power and to ancestors, human self-understanding of compassion, mercy, pity, wisdom, and so on.

Confucious's Zhong and $S h u$ were the specific implementations of Ren. In Confucianism Shu should be seen as a basic virtue. Although quite often translated as "altruism" or "putting oneself in Other's place", or even as "using oneself as a measure to gauge others", this concept can be elucidated in modern terms of strangification process, like extending from one person (Self) to the Other human or to the Other people.

The Confucian's scholar Mencius inherited the idea of "Ren" and expanded it into four fundamental criteria of relations between a human being and the world: Ren in itself, $Y i$ (righteousness, justice), Li (courtesy, propriety), Zhi (knowledge, wisdom). He was the main advocate of "the theory of good nature", which assumed four Human's spirits: compassion (Ren), a sense of shame (Yi), a sense of humility $(\mathrm{Li})$, a sense of right and wrong (Zhi).

From this historical retrospective let's turn up to the modern realization of these ideas.

Having drawn some ideas from Confucius and Mencius, we have stressed that the extension of Shu is implemented, basing on a reciprocal relation between Self and Other. With $S h u$, a human is spreading his/her own existence to larger and larger circles: from personal life to social, from individual qualities to national range, from one's internal and spiritual life to the common religious and moral existence. Consequently, we can sum up that Confucian being of a human is an expanding life based on the cultivation of Self, personal individuality, human's qualities.

This thesis could be considered like actual as well in the epoch of globalization. The principle of reciprocity has been remaining a guiding principle of Chinese social and political philosophy since the Great Learning of Confucius.

The philosophical ideas of the Canadian scholar are of interest due to his attempt to comprehend the Other, practicing the own deep philosophical tradition.

\section{GOD AS THE OTHER IN THE CONTEXT OF INTER- RELIGIOUS COMMUNICATION}

Another different point is the relation of Self with God like the Other.

For the religious persons (independent of their creed), God is the Other. The human's relation towards God is a personal intention to cognize Him and to become convinced of His presence. However, there is not reciprocal enrichment in the relations between a human being and God; vice versa, 
it's a one-sided drawing by an Individual of the best spiritual and moral notions from God. The mere Human apprehends the God's grace and His absolute qualities.

Upon touching the very delicate topic of religious communication (Person as Self and God as the Other), we have encountered those key questions:

When does God become the center of a personal life? Is He the Stranger to a believer? Am I able to become the Stranger for my internal activity when God exists in my spiritual life, having occupied a meaningful part of it? When and under what circumstances the God's "Other-position" might become my own?

\section{We have to describe it using historical approach.}

The peculiarity of human / God relations is being discussed in the Christian Patristic literature since the period of Early Christianity. The Church Fathers of Early Christianity underlined the idea of personal communion with the Christian Gog like an objective for each human being. It is possible to note in this sense the great creation of Saint John Climacus, also well known as John of the Ladder. He was the $7^{\text {th }}$-century Christian monk at the monastery on Mount Sinai. He wrote mostly for the monks and elaborated the concept of obtaining God via thirty steps of man's deification. The book "Ladder", written by John Climacus, described how to raise one's soul and body to God through the acquisition of ascetic virtues. It was the ladder or path of personal deification to gain the spiritual communion with the God. The twenty-ninth step was named "Love", first of all, "Love to all people". John Clumacus' followers, who were able to reach the level of "Love to people", could ascend to the final thirtieth step, titles "Love to God and God is love". Solely at this level, a human obtains communion, spiritual unity to God, having reached the objective (goal) of God's cognition and simultaneously personal self-cognition and self-purification.

The transformation of human nature and turn to the unity with God with the emergence of the "Other" was also described by Saint Afanasiy the Great. He writes: "The way to God isn't far from the Human, it isn't out of us, quite the contrary, it is inside us. And the starting of this way can be possibly found out personally. What is this way? - The soul of everybody and the mind inside it; because only mind is able to contemplate and cognize the God" [6; p. 165-166]. The aforementioned idea of the Saint Father signifies the overcoming of a dualistic nature of a Human being by the unity with God of personal, individual, free and rational human's nature.

In general, the early Christian writers underlined the concurrent process of God's cognition and individual's selfcognition. It was described as the "path to self", like the process of personal self-consciousness and self-creation through the search of moral ideals, comparison of one's behavior with Absolute morality of God, which was shown by Jesus Christ. Thus, the gradual personal ascendance to the communion with God has been radically changing a human essence, so that man becomes radically different compared to him at the very beginning of his religious quest.
Turning again to contemporary time, we would like to note that inter-religious (as cross-cultural) dialogue is very important for people of different cultural worlds. It is better for representatives of one religion to conceive the ideas of another religion through the awareness of morality and personal experience in cognition of Absolute reality of God and it would allow one to have access to God's various manifestations in religious diversity of modern global world. The mutual enrichment is better than conflict or war; the religious communication is better than political confrontation or cross-cultural and inter-religious conflicts.

Inter-religious and cross-cultural dialogues with the Others, like with the followers of a different religion or ethno culture can only start when one person steps outside of the self-limitation to meet the Other, facing and understanding cultural, religious, economical peculiarities and tolerantly share them. The philosopher Vincent Shen has stressed this notion in this sense: «I go outside of myself to you and you go outside of yourself to me, so as to form a dialogue leading to mutual enrichment. When we conduct mutual Waitui (strangification), we make our own scientific / cultural / religious life world understandable to each other by translating our languages into the language of the other's pragmatic context or by going through the detour of experiencing Reality Itself or the other's life-world. This process of mutual Waitui (strangification) is to be conducted not only in everyday life, in scientific research, in cultural and religious life, but also in economic and political life» $[5$, p. 5].

From our point of view religion allows overcoming an estrangement of one person from another. The idea of God (independent from kind of creed) has been uniting people since the origin of world's religions. Due to communication with God and human's intention of reaching spiritual presence of God in a personal life people are overwhelming cross-cultural problems, misunderstandings and finally are able to achieve unity and reciprocity.

The prominent Spanish philosopher of the $19^{\text {th }}-$ beginning of the $20^{\text {th }}$ centuries D. Miguel de Unamuno pointed out the human's need of God in the sense of universal Will and consciousness in order to get a sense of the life and to avoid nothingness. He wrote: "We have created God in order to save the Universe from Nothingness, for all that is not consciousness and eternal consciousness, conscious of its eternity and eternally conscious, is nothing more than appearance... And we need God in order to save consciousness; not in order to think existence, but in order to feel the wherefore of it. Love is a contradiction if there is no God" [7; p. 80-81].

Thus, according to M. Unamuno, life is consciousness in its connecting with God. God pertains to the ambit of the life and human beings can understand "the God of Unamuno" arriving from the life, feels, suffers, pity, loves, and desires, but not from reason or logic. So, everything that exists out of God, lacks consciousness and vice versa. In the context of existentialism, Unamuno has explained God as human's personal response to Him. The process of personalization demands a notion of God for conceiving himself / herself. 
For Unamuno, God is an idea that helps a human to universalize the world and understand self. God is the Other for an individual but without Him nobody can possess knowledge of Self. Without the Otherness there can't be consciousness and without consciousness can't be the Other. God permeates the life of the terrestrial world and combines the two worlds of the Selfness and the Otherness into one ontological notion of love. Love is a fundament for myself and the Other. «And we create God - that is to say, God creates Himself in us - by compassion, by love. To believe in God is to love Him, and in our love to fear Him; and we begin by loving Him even before knowing Him, and by loving Him we come at last to see and discover Him in all things» [7, p. 96].

There is also cognition of Self and the Others when we are all the strangers in the world. Nevertheless, only in the Others we can renew our life and so perpetuate ourselves.

\section{CONCLUSION}

The postmodern world, in our opinion, is much more difficult for the human perception than the preceding world of modernity. Philosophical-anthropological questions of our age are being gradually replaced by technology; they are "confiscated" in a sense by computers and other gadgets. However, it is impossible to strive for technology, simulating reality, viewing it as a supreme value, or denoting it as a role model. Russian religious philosopher N.A. Berdyaev, foreseeing the advent of technological civilization, detrimental for the sacredness of culture, warned: it is impossible for a human to disclose the depth of the inner world appealing to just nature. "From the lower the higher could not be born". A human being is a spiritual, divine creature. If we want to live in a real world, we have to return the real Other into our lives, personal and social, open our hearts and minds to Love, compassion, mercy. Thus, our Self and the Other/Others become a natural extension for each other and not the complete strangers.

Religion is playing a crucial role for many people and thus conveying the ideas of spiritual and intercultural communications among humans of different denominations since their emerging. Awareness of the current state of social affairs reminds us that religion should not be forced out (or underestimated) from the sphere of social and cultural life, especially from the sphere of existential life of each person.

Each society has to rely on religious organization in the matter of social working, of reestablishing the relations among people of different confessions, cultures, ethnicities, and, what is the most important, in re-learning to be a human in times of global alienation and strangification, which has been named globalization.

\section{REFERENCES}

[1] Grechko P. K. Social Theory of Modernity. - M.: PFUR, 2008

[2] Debord, G. Society of the Spectacle. - Detroit: Black and Red. 1983.

[3] Baudrillard, J. Symbolic Exchange and Death. - Moscow: Dobrosvet, 2009.
[4] Sartre Jean-Paul, Existentialism and a Humanism. Yale university press. 2007.

[5] Shen Vincent. Confucian Altruism, Generosity and Justice: A Response to Globalization // Washington, DC. Council for Research in Values and Philosophy, CUA. 2016.

[6] Afanasiy the Great. The Creations. In 2 vol. Vol. 1. - Moscow. Bogosloviye. 1994.

[7] Miguel Unamuno. Tragic sense of Life. Dover Publication, INC. New York, 2005. 